\title{
Isolation, Purification and Characterization of Pectinase Enzyme from Streptomyces Thermocarboxydus
}

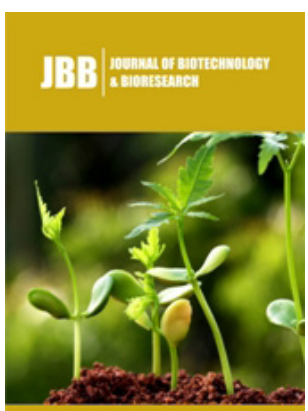

*Corresponding author: Priyanka SB, Department of Biotechnology, India

Submission: March 07, 2019

Published: 僵April 17, 2019

Volume 1 - Issue 5

How to cite this article: Priyanka $S$. Isolation, Purification and Characterization of Pectinase Enzyme from Streptomyces Thermocarboxydus. J Biotech Biores.1(5). JBB.000523.2019.

Copyright@ Priyanka SB, This article is distributed under the terms of the Creative Commons Attribution 4.0 International License, which permits unrestricted use and redistribution provided that the original author and source are credited.

\author{
Priyanka SB* \\ Department of Biotechnology, India
}

\begin{abstract}
Pectinases, commonly referred to as pectic enzymes, are an important class of enzymes for their uses in industries like wine, paper, and food for the processing of fruits, vegetables, tea, coffee, and can be extracted from actinomycetes, a group of bacteria popular for research for such products as the penicillin and pectinases. Such pectinase enzymes that will work at high temperatures and at appropriate $\mathrm{pH}$ conditions can be of benefit at high temperatures, which can be used to speed up these processes. Speed of processing gives an economic gain in commercial applications. This study involved the isolation, purification and characterization of pectinase enzyme from Streptomyces thermocarboxydus.
\end{abstract}

Soil bacterial isolation resulted in seventeen different types of colonies and these from petri were transferred to agar and cultured on pectin containing media at $37{ }^{\circ} \mathrm{C}$ temperature, and the strain showing maximum pectin clearing detected with iodine vapor. The selected isolate was first sent for sequencing using rRNA technology and phylogenetic analysis. Experiments for culture optimization and enzyme characterization were carried out. The optimum $\mathrm{pH}$ and temperature for culture was found out to be 4 and $50^{\circ} \mathrm{C}$, and for the partially purified enzyme, maximum activity, at neutral and alkaline $\mathrm{pH}$ and $60^{\circ} \mathrm{C}$. Hence, this enzyme proves to be a promising candidate for commercial applications..

Keywords: Actinomycetes; Pectinase; Enzymatic optimization; Phylogenetic analysis; Streptomyces thermocarboxydus

\section{Introduction}

Pectin is a naturally occurring substance (A Polysaccharide) found in berries, apples and other fruits. When heated together with sugar, it causes a thickening that is characteristic of jams and jellies. It is a structural heteropolysaccharide contained in the primary cell walls of terrestrial plants. It was first isolated and described in 1825 by Henri Braconnot, a chemist and pharmacist, who for the first-time depolymerized chitin with acid. Pectin is a complex polysaccharide consisting mainly of esterified D-galacturonic acid resides in an alpha-(1-4) chain. Diagram below shows picture of the structure of pectin (Figure 1). Commonly referred to as pectinases, pectic enzymes, are an enzyme that breaks down pectin. They are an important class of enzymes for their uses in industries like wine, paper industries and food industry for the processing of fruits, vegetables, tea, coffee and so on.

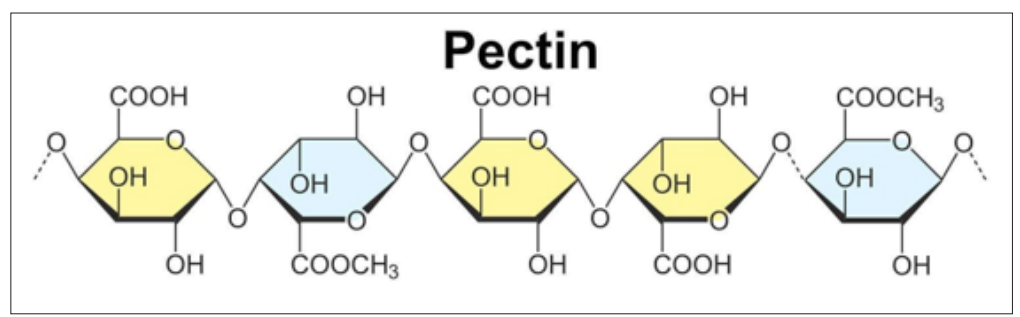

Figure 1.

\section{Pectinase, the enzyme}

Pectinases include pectolyase (pectin lyase), pectozyme, and polygalacturonase (PG) of the three, PG, is the most well studied. PG, hydrolyses the O-glycosyl bonds in pectin's polygalacturonan network, resulting in alpha-1,4-polygalacturonic residues. The rate of 
hydrolysis is dependent on polysaccharide chain length. Rate of hydrolysis is slow with very short chains (e.g. Digalacturonic Acid) and very long chains. The picture below shows the hydrolysis of pectin by polygalacturonan network, resulting in alpha-1,4Polygalacturonic residues (Figure 2).

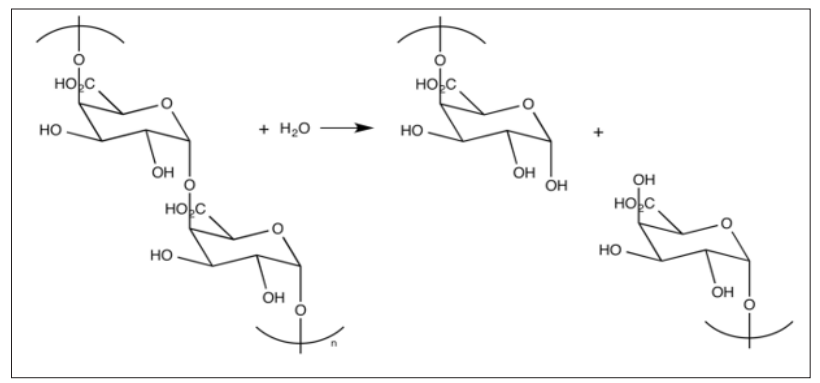

Figure 2.

\section{Pectinases from fungi and bacteria}

Pectinases act on pectin substances. It is naturally present in higher plants and microorganisms. In plants, it hydrolyses the cementing pectin in cell wall to allow remodeling and growth during development. In microorganisms, such fungi, they help to break the pectin to saprophyte, while the mushrooms hyphae use these enzymes to do the same as it grows and absorbs the nutrients. Commercially, these pectinases are used extensively in several different processes that include fruit juice clarification, juice extraction, manufacture of pectin free starch, refinement of vegetable fibers, degumming of natural fibers, wastewater or sewage treatment. They also find their use in cocoa and tobacco industry towards their end-production, and as an analytical tool in the assessment of plant products [1]. In tea and coffee, pectinase treatment accelerates tea fermentation and destroys pectin the foam forming property and remove mucilaginous coat from coffee beans [1].

Pectinolytic enzymes can be applied in various industrial sectors wherever the degradation of pectin is required for a process. Several microorganisms have been used to produce different types of pectinolytic enzymes [2] Microbial pectinases account for $25 \%$ of the global food and industrial enzyme sales [3] and their market is increasing day by day. These are used extensively for fruit juice clarification, juice extraction, manufacture of pectin free starch, refinement of vegetable fibers, degumming of natural fibers, wastewater treatment, and cocoa and tobacco and as an analytical tool in the assessment of plant products [4]. Pectinase treatment accelerates tea fermentation and also destroys the foam forming property of instant tea powders by destroying pectins. They are also used in coffee fermentation to remove mucilaginous coat from coffee beans [5].

Due to the importance of the pectinase enzyme in biotechnology, lot of researchers have attempted isolation of species that express pectinase, and that are hence, of benefit. One such a study was conducted with the aims of screening pectinolytic microorganisms from coffee pulp and identifying molecularly using 16S rRNA. Another study records the studying of such species enriched in fruit material.

\section{Actinomycetes: Primer}

Actinobacteria are Gram-positive bacteria with high $\mathrm{G}+\mathrm{C}$ DNA content. The majority of the Actinobacteria are free-living organisms that are widely distributed in both terrestrial and aquatic (Including Marine) ecosystems [6]. Actinomycetes hold a prominent position as targets in screening programmed due to their diversity and their proven ability to produce novel antibiotic and non-antibiotic lead molecules of pharmaceutical interest.

\section{Actinomycetes-classification}

Actinobacteria represent one of the largest taxonomic units among the 18 major lineages currently recognized within the Bacteria domain. Actinomycetales are Gram-positive, but several species have complex cell wall structures that make the Gram staining unsuitable (e.g. Mycobacteriaceae). The genera of this phylum exhibit enormous diversity in terms of their morphology, physiology, and metabolic capabilities. The taxonomy of Actinobacteria has evolved significantly over time with the accumulation of knowledge. The early classification by Buchanan in 1917 placed this bacterium as the order Actinomycetales. The classification of these bacteria has now evolved from microscopy morphological, to melanin pigment, and chemo taxonomical, to rRNA to genome sequencing and to new molecular methods of classification. However, actinomycetes have the appearance of filaments or hyphae, superficially resembling many forms of hyphal fungi.

Actinobacteria exhibit a wide variety of morphologies, differing mainly with respect to the presence or absence of a substrate mycelium or aerial mycelium, the color of the mycelium, the production of diffusible melanoid pigments, and the structure and appearance of their spores. Chemotaxonomic classification: Chemotaxonomy is the use of the distribution of chemical components to group organisms according to the similarities of their cellular chemistries [7]. The most commonly used chemical components in such systematics are cell wall amino acids, lipids, proteins, menaquinones, muramic acid types, sugars, and the base composition of DNA [8]. At present, a new species cannot be claimed without genetic analysis based on sequencing the 16S rRNA gene and DNA-DNA hybridization, and even genome sequencing is becoming a routine testing. Molecular and chemical composition criteria have been used to group the order Actinomycetales into 14 named suborders. The 16S rRNA gene trees have now been generated with bootstrap support and may thus include fewer misleading results.

\section{Actinomycetes-their products}

Since the discovery of actinomycin, the first antibiotic from an actinomycete, many commercially important bioactive compounds and anti-tumor agents have been produced using these bacteria [9]. The anti-infective turn-over of over 79 billion US dollars in 2009, includes about 166 antibiotics and derivatives such as the Betalactam peptide antibiotics, the macrolide polyketide erythromycin, tetracyclines, aminoglycosides, daptomycin, tigecycline, most of which are produced by actinomycetes. Actinomycetes are the 
also producers of many natural antitumor compounds. These antitumor compounds belong to several structural classes such as anthracyclines, enediynes, indolocarbazoles, isoprenoids, macrolides, non-ribosomal peptides and others.

They exert antitumor activity by inducing apoptosis through DNA cleavage mediated by topoisomerase I or II inhibition, or mitochondrial permeabilization, or inhibition of key enzymes, involved in signal transduction like proteases, or cellular metabolism and also by inhibiting tumor-induced angiogenesis. A surge of recent researches is seeing marine organisms that have attracted special attention in the last years for their ability to produce interesting pharmacological lead including antitumour compounds. In this present study, our aim is two-fold. To determine the culture optimization to obtain a pectinase producing bacteria that works at high temperatures and to determine enzyme characterization. In order to do this, we aim to isolate culture soil bacteria on agar, and then grow the isolates on petri with agar containing pectin. The isolate with the largest pectin clearance is then to be sent for rRNA technology and phylogenetic analysis. Culture optimization and enzyme standardization are also to be carried out on this isolate and also on partially purified enzyme.

\section{Materials and Methods}

\section{Isolation and sub-culturing}

Isolation: Ingredients starch casein nitrogen agar (g/litre), Soluble starch 10.00, Casein (Vitamin Free), 0.30, $\mathrm{KNO}_{3}, 2.00$, $\mathrm{MgSO}_{4} \cdot 7 \mathrm{H}_{2} \mathrm{O}, 0.05, \mathrm{~K}_{2} \mathrm{HPO}_{4}, 2.00, \mathrm{NaCl}, 2.00, \mathrm{CaCO}_{3}, 0.02, \mathrm{FeSO}_{4} .7 \mathrm{H}_{2} \mathrm{O}$, 0.01 , Agar, 18.00. Bacteria from soil sample was collected and the sample diluted, starch casein nitrogen agar was prepared and poured onto sterile autoclaved petri plates, allowed to cool, and the diluted sample transferred. The plates were incubated at $31.5^{\circ} \mathrm{C}$ and growth was observed after a week. This Isolation saw seventeen microorganism colonies.

Sub-culturing: Sub-culturing involved each of these organisms being screened for pectinase on pectinase screening agar medium (PSAM) by streaking them

\section{Pectinase production medium}

PSAM: It was prepared as per the following composition: $0.3 \mathrm{gms} / 100 \mathrm{ml}, \quad\left(\mathrm{NH}_{4}\right) 2 \mathrm{HPO}_{4^{\prime}} \quad 0.2 \mathrm{gms} / 100 \mathrm{mlKH}_{2} \mathrm{PO}_{4^{\prime}}$ $0.3 \mathrm{gms} / 100 \mathrm{ml}, \mathrm{K}_{2} \mathrm{HPO}_{4}, 0.01 \mathrm{gms} / 100 \mathrm{mlMgSO}_{4}, 2.5 \mathrm{gms} / 100 \mathrm{ml}-$ Agar, 1gm/100ml-Pectin and PH-4.5

\section{Identification of isolate with largest clear-zone}

They (Petris) were incubated at $37{ }^{\circ} \mathrm{C}$ in the incubator and growth was observed in 4 days. The plates were exposed to iodine vapours such that the clear zones were visible. The clear zones were measured and compared to find the biggest clear zone. The organism having the biggest clear zone has higher pectinase producing ability. The chosen organism was named isolate IS-1. The isolate was sent for sequencing using rRNA technology and phylogenetic analysis. IS-1 Culture optimization was carried out by optimizing organism under varying conditions of temperature and $\mathrm{pH}$

\section{Culture-temperature \& $\mathrm{pH}$ value optimization, and production of crude enzyme}

The IS- 1 is incubated in pectinase broth under varying $\mathrm{pH}$ such as 4, 7 and 12 . Similarly it is incubated at varying temperatures of $31{ }^{\circ} \mathrm{C}, 50^{\circ} \mathrm{C}$ and at room temperature for culture conditions. After 3 days of incubation, the media from each flask was centrifuged at 10,000rpm and crude enzyme was obtained. The culture -temperature optimization and $\mathrm{pH}$ value optimization curves were calibrated using DNS assay and Lowry method of protein assay. $1 \mathrm{ml}$ of substrate (pectin) dissolved in suitable buffer was made to react with the respective crude enzymes for $20 \mathrm{~min}$ at $35^{\circ} \mathrm{C}$. The concentration of substrate was determined by DNS method. $10 \mathrm{ml}$ of water was added for dilution before taking the optical density reading.

\section{Partial purification by ammonium sulphate method, and enzymatic optimization: temperature \& pH}

For the Ammonium sulfate precipitation method of partial purification, crude enzyme obtained was kept in cold conditions throughout, and ammonium sulfate was added to it gram by gram and stirred continuously until all of the Ammonium sulfate was used completely. The set up was left in cold conditions in the refrigerator overnight. The following morning, the precipitate was collected and centrifuged at $4{ }^{\circ} \mathrm{C}$ and the protein obtained was dissolved in citrate buffer of $\mathrm{pH}$.

\section{Characterization of partially purified enzyme}

The partially purified enzyme which was obtained after ammonium sulphate precipitation was characterized at different $\mathrm{pH}(5,7,9,12)$ and Temperature $\left(20^{\circ} \mathrm{C}, 25^{\circ} \mathrm{C}, 40{ }^{\circ} \mathrm{C}, 60{ }^{\circ} \mathrm{C}, 80^{\circ} \mathrm{C}\right.$ and $100{ }^{\circ} \mathrm{C}$ ) using DNS method, and graph plotted for enzyme activity versus $\mathrm{pH}$ and enzyme activity versus temperature.

\section{Purification by dialysis method}

The partially purified enzyme was loaded in the activated dialysis membrane tube and was let to undergo dialysis for 18 hours at $40{ }^{\circ} \mathrm{C}$ with Citrate buffer. The buffer was also changed in between to ensure efficient dialysis. The dialyzed sample was frozen at -200 ${ }^{\circ} \mathrm{C}$ for 2 hours. The sample was now kept for lyophilization in a lyophilizer.

\section{Result and Discussion}

\section{Result}

This section shows the result of the experiments, which are as follows:

A. pH optimization results

B. Temperature optimization results

C. Results of sequencing using rRNA technology, and phylogenetic analysis

\section{pH optimization results}

Graph a. pH optimization. The graph below shows the culture optimisation and enzyme characterisation, for $\mathrm{pH}$. for the studied 
bacteria and the enzyme, pectinase (Figure 3). $\mathrm{pH}$ optimisation Graph above shows the culture optimisation and enzyme characterisation for $\mathrm{pH}$ for the studied bacteria and the enzyme, pectinase. The culture conditions were optimized and the optimum $\mathrm{pH}$ for the culture was found to be 4 . The partially purified enzyme is seen to show maximum activity at neutral and alkaline $\mathrm{pH}$.

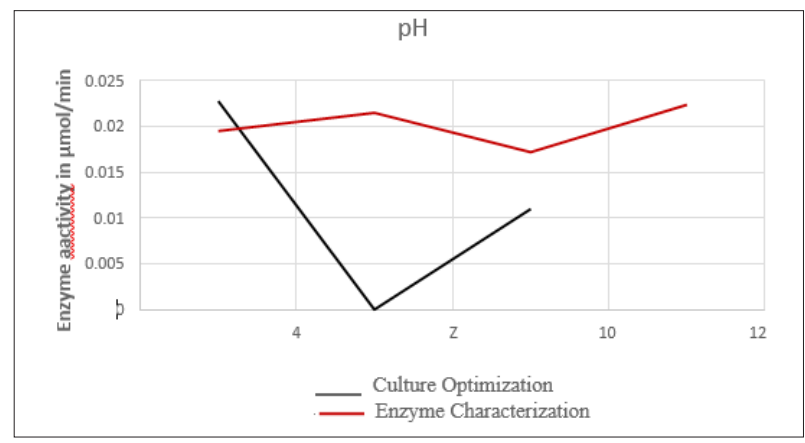

Figure 3.

\section{Temperature optimization results}

(Figure 4) Figure shows relation between Temperature and Enzyme activity. The partially purified enzyme was found to have its optimum activity at $60^{\circ} \mathrm{C}$. The culture conditions were optimized and the optimum temperature for the culture was found to be $50{ }^{\circ} \mathrm{C}$.

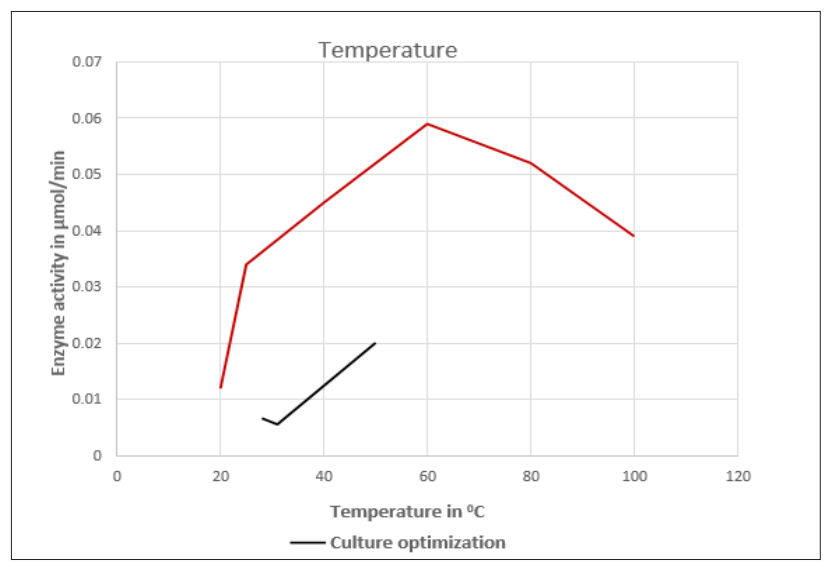

Figure 4.

Result of sequencing using rRNA technology, and phylogenetic analysis

IS-1 had the biggest clear zone among all the seventeen isolates in the pectinase screening test. The chosen organism was isolate IS-1. The isolate was sent for sequencing using rRNA technology and for phylogenetic analysis. The isolate was found, by this rRNA technology, to be Streptomyces thermocarboxydus

Table 1: NCBI r RNA blast result.
A. The sequence: Result of sequencing

>ACT19R_Seq92

C T C C C AAGAG T T T GAT CAT G G C T C AAGGACGAACG C TGGCGGCGTGCTTAACA CATGCAAGTCGAACGATGAAGCCCTTTCGGGGTGGATTAGTGGCGAACGGGTG AGTAACACGTGGGCAAT CT GCCC TGCACTATGGGGACAAG CCC TGGAAACGGG GICTAATACOGGATACTGATOCOCTTGGGCATOCTTGGTGATOGAAAGCTOCGCGOGTGCAGGATGAGGCCGCGGCCTATCAGCTTGTTGGTGAGGTAATGGCTCAC CAAGGCGACGACGGGTAGCCGGCCTGAGAGGGCGACCGGCCACACTGGGACT GAGACACGGCCCAGACTCCTACGGGAGGCAGCAGTGGGGAATATTGCACAAT GGGCGAAAGCCTGATGCAGCGACGCCGCGTGAGGGATGACGGCCTTCGGGTTGTAAACCTCTTTCAGCAGGGAAGAAGCGAAAGTGACGGTACCTGCAGAAGAAG CGCCGGCTAACTACGTGCCAGCAGCCGCGGTAATACGTAGGGCGCGAGCGTTG TCCGGAATTATTGGGCGTAAAGAGCTCGTAGGCGGCTTGTCGCGTCGGTTGTG

AAAGCCCGGGGCT TAACC CCGGGTCTGCAGTCGATACG GGCAGGCTAGAGTTC GGTAGGGGAGATCGGAATTCCTGGTGTAGCGGTGAAATGCGCAGATATCAGGA GGAACACCGGTGG C GAAG GCGGAT C TC T G G G C C GATAG T GACGG T GAG GAG C GAAAGCGTGGGGAGCGAACAGGATTTGTACCCTGGTAGTCCACGCCGTAAACG GTGGGCACTAGGGTGTGGGGCGACATTCAGTGTCGAAGAGAAGCGGTCTGAAT ATAGCC

B. NCBI-BLAST results (Top 5-10 Hits) - bi. Table, NCBI rRNA blast result: The blast gave the following strains of the same species, the Streptomyces, with their corresponding Ident, the percentage rRNA sequence homologies (Table 1).

C. Phylogenetic Tree (along with scale bar and bootstrap values above 50\%): NR 043835.1 Streptomyces pseudogriseolus strain NRRL (Figure 5).

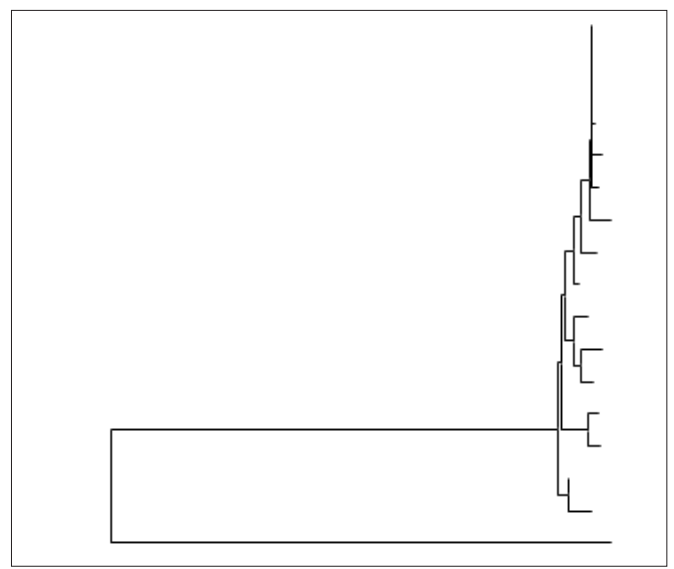

Figure 5.

\begin{tabular}{|c|c|c|c|c|c|c|}
\hline Description & Max Score & Total Score & $\begin{array}{c}\text { Query } \\
\text { Cover }\end{array}$ & E Value & Ident & Accession \\
\hline $\begin{array}{c}\text { Streptomyces thermocarboxydus strain NBRC 16323 } \\
\text { 16S ribosomal RNA gene, partial sequence }\end{array}$ & 2052 & 2052 & $97 \%$ & 0 & $98 \%$ & NR_112585.1 \\
\hline Description & Max score & Total score & Query cover & E value & Ident & Accession \\
\hline
\end{tabular}




\begin{tabular}{|c|c|c|c|c|c|c|}
\hline $\begin{array}{l}\text { Streptomyces thermocarboxydus strain AT37 16S } \\
\text { ribosomal RNA gene, partial sequence }\end{array}$ & 2047 & 2047 & $97 \%$ & 0 & $98 \%$ & NR_026072.1 \\
\hline $\begin{array}{l}\text { Streptomyces rubiginosus gene for } 16 \mathrm{~S} \text { ribosomal } \\
\text { RNA, partial sequence, strain: JCM } 4416\end{array}$ & 2002 & 2002 & $99 \%$ & 0 & $97 \%$ & LC034307.1 \\
\hline $\begin{array}{l}\text { Streptomyces pseudogriseolus strain NRRL B-3288 } \\
\text { 16S ribosomal RNA gene, partial sequence }\end{array}$ & 2001 & 2001 & $99 \%$ & 0 & $97 \%$ & NR_043835.1 \\
\hline $\begin{array}{l}\text { Streptomyces speibonae strain PK-Blue 16S ribosomal } \\
\text { RNA gene, partial sequence }\end{array}$ & 1997 & 1997 & $99 \%$ & 0 & $97 \%$ & NR_025212.1 \\
\hline $\begin{array}{l}\text { Streptomyces indiaensis strain NBRC } 13964 \text { 16S ribo- } \\
\text { somal RNA gene, partial sequence }\end{array}$ & 1995 & 1995 & $97 \%$ & 0 & $97 \%$ & NR_041155.1 \\
\hline $\begin{array}{l}\begin{array}{l}\text { Streptomyces nigra strain } 452 \text { chromosome, complete } \\
\text { genome }\end{array}\end{array}$ & 1991 & 11950 & $99 \%$ & 0 & $97 \%$ & СР029043.1 \\
\hline $\begin{array}{l}\text { Streptomyces sp. strain } 45216 \text { S ribosomal RNA gene, } \\
\text { partial sequence }\end{array}$ & 1991 & 1991 & $99 \%$ & 0 & $97 \%$ & MG572975.1 \\
\hline
\end{tabular}

yces bellus strain NBRC 12844 NR 043840.1 Streptomyces variables strain NRRL B-3984 NR 112487.1 Streptomyces albogriseolus strain NBRC 3413 NR 041155.1 Streptomyces indiaensis strain NBRC 13964 NR 041070.1 Streptomyces massasporeus strain NBRC 12796 NR 112585.1 Streptomyces thermocarboxydus strain NBRC 16323

\section{Discussion}

The selected 'Isolate' was first sent for sequencing using rRNA technology and phylogenetic analysis. Experiments for culture optimization and enzyme characterization were carried out. The optimum $\mathrm{pH}$ for the culture was found to be 4 and temperature was found to be $50^{\circ} \mathrm{C}$. For the partially purified enzyme, maximum activity was at neutral and alkaline $\mathrm{pH}$, and the optimum temperature was $60^{\circ} \mathrm{C}$. Hence, this enzyme proves to be a promising candidate for commercial applications, where high temperatures may be benefitting faster reaction and hence more economically viable processes can be achieved to meet the increasing demand of the products. The focus of this study was to obtain a pectinase that could withstand higher working temperatures for commercial applications. Soil bacteria were isolated, and the isolates plated on pectin containing agar, which resulted in giving IS-1, an isolate with the highest pectin clearance.

This selected isolate was first sent for sequencing using rRNA technology and phylogenetic analysis. The result of this sequencing and analysis are discussed later below. Culture optimisation and enzyme characterization were carried out for $\mathrm{pH}$ and temperature. Graph, in Figure 1. results, shows relation between 'pH vs Culture growth' and 'pH vs enzyme activity'. The culture conditions were optimized and the optimum $\mathrm{pH}$ for the culture was found to be 4. The partially purified enzyme shows maximum activity at both neutral and alkaline $\mathrm{pH}$. The optimum $\mathrm{pH}$ for the culture is determined to be acidic while that for the partially purified enzyme is neutral and alkaline. Culture refers to the growth of the whole organism. The $\mathrm{pH}$ for this culture growth when optimized is acidic because the organism has evolved to live in the acidic environment. The optimum $\mathrm{pH}$ for the enzyme is neutral or alkaline, meaning that internal environment of the bacteria must be maintained at neutral or alkaline conditions [10].
During growth at acidic $\mathrm{pH}$ values, Streptococcus can increase production of their F-ATPases. By pumping protons out of cells, these proton pumps can function to assist in maintaining or even increasing internal pH values [11]. Respiration by the bacteria, under aerobic conditions releases carbon dioxide, and while reacting with water turns its surrounding acidic. The Streptococcus can also be facultative anaerobic. The partially purified enzyme was found to have its optimum activity at $60^{\circ} \mathrm{C}$. The culture conditions were optimized and the optimum temperature for the culture was found to be $50{ }^{\circ} \mathrm{C}$, ten degrees less than for the partially purified enzyme. The culture, consisting of the whole organism has other enzymes such as the respiratory enzymes, that may be sensitive at higher temperatures, and hence a temperature above $50{ }^{\circ} \mathrm{C}$ would begin to degrade it.

Moreover, the sampling was done in a tropical country and hence the higher temperature tolerance evolution is evident. Of course, it must be noticed that the enzyme has its optimum activity at $60{ }^{\circ} \mathrm{C}$, and this is unusually higher as we would have expected the optimum temperature to have been around the region of the soil temperature, say about 35 to $40{ }^{\circ} \mathrm{C}$. The organism must be a result of evolution and gain mutation, which enables to work at such a high temperature of $60^{\circ} \mathrm{C}$. The result is that we identified a species that produces pectinase that is tolerant and optimal at higher temperatures, of about $60^{\circ} \mathrm{C}$. The main use of this particular enzyme is that, this high temperature tolerant enzyme can be of immense use in industrial applications where speed of process may be necessary for increased economics.

\section{6s rRNA technology based sequencing and phylogenetic analysis}

The isolate that is found to give the largest pectin clearance was sent for identification by rRNA sequencing technology and phylogenetic analysis. The isolate is found to have $99 \%$ homology or sequence match with the species Streptomyces thermocarboxydus strain, NBRC 16323. The phylogenetic analysis further tells us the closeness of this species-strain to another species-strain of this same species, the Streptomyces, with the bootstrap value, of course, the closeness or distance to a number of closely-related species. 


\section{The Phylogenetics-the bootstrap explained}

The bootstrap value gives the chance value of this species strain occurring in its closeness to the neighboring species or species strain under study. The closest Streptomyces strain to this identified strain is, NR 041102.1 Streptomyces variabili, is strain NBRC 13046 with a bootstrap of $97 \%$ chance of it being in its place. Of course, the 97\% indicates that there might be another or other species with the same chance of $97 \%$ being in the place of this strain, the strain Streptomyces pseudogriseoloalbus. The next strain that is closest in the phylogeny as it stands at the moment is the NR 041102.1 Streptomyces griseoloalbus strain NBRC 13046 with a bootstrap value of $91 \%$.

\section{Conclusion}

The identification of the other species-strains closes to the Streptomyces thermocarboxydus strain under analysis will help find other species-strains that may be close to this speciesstrain under analysis and hence there is a possibility of getting a mutant enzyme pectinase, that maybe more resistant to higher temperatures as compared to the enzyme that is found in this study. The uses of the pectinase enzyme in commercial application can be seen in everyday life and can be seen in the production lines including fruit juices and wine brewing. To conclude, it must be noted that our study and such studies involving phylogenetics, culture optimization and enzyme standardization can help find enzymes that have a more useful temperature withstanding abilities to the one in hand, either for this application or for others. It can also be taken a step further, and controlled mutations of this enzyme can also help produce a sequence and hence find enzyme that is slightly different and more effective than, probably, all that may be present in the close existing species.

\section{Acknowledgment}

Wish to acknowledge with thanks expert suggestions, advice and technical support provided by Prof. S A Gautham and Prof.
Sunil Moray, Dean and Prof-Dept. of Life Sciences, Dayananda Sagar University, Bangalore. Would also like to express sincere thanks to NCIM, Pune for their technical help on 16s rRNA technology sequencing.

\section{References}

1. Oumer J, Abate D (2019) Screening and molecular identification of pectinase producing microbes from coffee pulp. Biomed Res Int 2018.

2. Jayani S, Shukla K, Gupta R (2010) Screening of bacterial strains for polygalacturonase activity: Its production by bacillus sphaericus (MTCC 7542). Enzyme Res 2010: 1-5.

3. Jayani S, Saxena S, Gupta R (2005) Microbial pectinolytic enzymes: A review. Process Biochemistry 40(9): 2931-2944.

4. Alkorta I, Garbisu C, Llama J, Serra L (1998) Industrial applications of pectic enzymes: A review. Process Biochemistry 33(1): 21-28.

5. Sieiro C, García B, López J, Silva A, Villa G (2012) Microbial pectic enzymes in the food and wine industry. Food Industrial Processes-Methods and Equipment: 201-218.

6. Macagnan D, Romeiro S, Jorge $\mathrm{T}$, Pomella V (2006) Isolation of actinomycetes and endospore-forming bacteria from the cacao pod surface and their antagonistic activity against the witches' broom and black pod pathogens. Phytoparasitica 34(2): 122-132.

7. Goodfellow M, Minnkin E (1985) Chemical methods in bacterial systematics. Academic Press, London, UK.

8. Donnell G (1988) Recognition of novel actinomycetes. In: Goodfellow M, Williams T, Mordarski M (Eds.), Actinomycetes in biotechnology. Academic Press, London, UK.

9. Information on EC 3.2.1.15 - Polygalacturonase. Brenda, Germany.

10. Pressey R, Reger J (1989) Polygalacturonase in pollen from corn and other grasses. Plant Science 59(1): 57-62.

11. Corcoran B, Stanton C, Fitzgerald G, Ross R (2005) Survival of probiotic lactobacilli in acidic environments is enhanced in the presence of metabolizable sugars. Applied and Environmental Microbiology 71(6): 3060-3067.

For possible submissions Click below: 